\title{
Research on the U-K Collaborative Cultivating Model of "Outstanding Preschool Teachers" in Local Normal University
}

\author{
Bo-Qiong TIAN \\ Education Department, Chongqing Normal University, Chongqing, China \\ 835987477@qq.com
}

Keywords: University and kindergarten, Collaborative training model, Outstanding preschool teacher.

\begin{abstract}
The outstanding preschool teachers are the important resource in the early children education .The traditional teacher training only relying on the colleges will be inevitably closed. This research is based on the outstanding preschool teachers' core capabilities to study the U-K collaborative model to train the outstanding preschool teachers.
\end{abstract}

\section{The Research Background}

Along with the education influence on the personal destiny and their future life quality is increasing, the public's desire for quality education is increasingly strong, high quality school education can't be separated from the excellent teaching staff has become the consensus of the people. The national long-term education reform and development plan (2010-2020) pointed out:" the education policy based on good teachers ". Cultivating high quality and specialized teaching staff is the basic mission of teacher education. with the continuous education reform, teacher education quality in our country has improved, but the traditional teacher training only relying on the colleges will be inevitably closed, as result, teachers' knowledge structure is single, teaching practice ability is weak, reforming the teacher training mode is urgently needed. In 2014, the ministry of education about views on implementation of outstanding teachers training plan clearly pointed out: "deepen the teacher training reform, establish colleges and universities and the local governments, schools (kindergarten, secondary vocational schools, special education schools) collaborative training mechanism, train a large number of primary and secondary school teachers with noble morality, solid professional foundation, teaching ability and self professional development ability", which marks a new stage of history in the teacher education reform in our country.

The preschool education is an important part of the national education system and the foundation for lifelong learning and overall development. How to build outstanding preschool teachers is very important. the ministry of education about views on implementation of outstanding teachers training plan clearly pointed out: "classified promoting the reform preschool outstanding teacher training mode, to adapt to the development of preschool education reform, constructing an integrated training system with deep foundation, strong ability, cultivate a group of outstanding preschool teachers who have comprehensive quality and teaching ability, they love preschool education." The colleges has been unable to undertake to train outstanding preschool teachers, many colleges and universities are trying to work with kindergartens to cultivate outstanding preschool teachers, but many aspects of cooperation are still a mere formality, It is still difficult to get rid of the shackles of the "professionalism" with taking theoretical knowledge seriously and ignoring the practical skills. Local Normal University as an important base for training preschool teachers, exploring the U-K collaborative training model (U-K collaborative training model means that the university and kindergarten train the preschool teachers through sharing, cooperation, integration mechanism) is a practical significance of local normal university in cultivating teachers. This research is based on the outstanding preschool teachers' core capabilities to study the U-K collaborative model to train the outstanding preschool teachers. 


\section{Outstanding Preschool Teachers’ Core Capabilities}

Outstanding means that the pursuit of better, it means to constantly surpass oneself, to avoid oneself into a certain set of patterns and conditions, expanding and sublimating their own potential(Liu Xiangrong,2012) Outstanding preschool teachers should have the following basic core capabilities.

\section{Noble Professional Ethics}

Teachers' occupation ethics includes teachers occupation attitude and understanding, trust and the spirit of the occupation, occupation expectations (Shi Yudan, Lu Xiaozhong, 2015). Only with noble occupation moral, will the teachers love the educational cause. Therefore, occupation moral level is a measure of the most basic indicators. Outstanding preschool teachers' occupation morality is mainly manifested in the following aspects: (a) The deep occupation emotion, the occupation emotion reflects the occupation identity and sense of belonging, which is the inner motivation of teachers' professional development. (b) The occupation attitude of making oneself an example. Outstanding preschool teachers are children's learning resources, as well as the resources which support the growth of new teachers. So they should have positive attitude to their own work. (c) Keep making progress and pursuit of excellence professional ideal. As an excellent preschool teacher, with the career development of the ideal, have a clear career development goal and continuous improvement, the pursuit of excellence in professionalism.

\section{Profound Professional Knowledge and Extensive General Knowledge}

Profound professional knowledge is an important capability of outstanding preschool teachers. It mainly includes the following aspects: (a) Solid professional knowledge and academic capability, which include the knowledge of children's development and children care and education. The outstanding preschool teachers should understand the characteristics of children's physical and mental development and grasp the strategies of children care and education knowledge. (b) The outstanding preschool teachers should have a broad general knowledge. Early children education is comprehensive activities, the teachers not only need the psychology and pedagogy knowledge, but also need more humane social science, history and culture, natural science knowledge and so on.(c) The outstanding preschool teachers should know the of policy and law to understand the teachers and children's right and duty. The modern society is a society ruled by law, the relationship between teachers and children not only includes the traditional ethical, emotional content, but also to the contract and the rational direction.

\section{Solid Professional Skills}

Solid professional ability is an important factor to improve the education quality, outstanding preschool teachers' professional ability mainly includes the keen observation ability, curriculum resources development ability, the curriculum design, teaching organization and implementation capacity, reflective ability, good communication skills.

\section{Independent Educational Research Ability}

Educational research is a powerful means to break through in the education confusion. The outstanding teachers' education and teaching isn't only the process of the "teaching" and "learning", but the organic combination of the inquiry process with "thinking” and "research". (Wang Zhiguang, 2013) The outstanding teachers should be good at extracting the advanced educational theory from the practice of teaching reform to provide theoretical support and encouragement for their own goals. Promoting teaching with scientific research, carrying out in-depth research in teaching, so that they can eventually reach the realm that is more easily. Independent educational research is the most direct quickly and effectively way for outstanding preschool teachers to obtain cutting-edge knowledge and theory. The teacher who is able to teach is a good teacher, the teacher who is able to research is also a good teacher, the teacher who is both able to teach and research is excellent teachers. 


\section{Professional Guidance}

Outstanding preschool teachers should not only pass the individual experience, but also lead the team's overall development. This is the outstanding preschool teachers realize the value from personal to the social value. The other Teachers pay attention to the professional guide of outstanding teachers, which reflect the sense of expectation of teachers to outstanding teachers. So the outstanding preschool teachers should share and the valuable experience with the others, and let more teachers get more benefit.

\section{The Research on the U-K Collaborative Training Model}

\section{Improve the Security System of U-K Cooperation}

To improve the security mechanism is U-S long-term cooperation protection. First of all, it is necessary to establish the cooperation policy between the university and kindergarten base on the local government. Second, the reliable funding, which provides the sufficient financial support for the development of high quality educational resources, teacher training, research cooperation, development of high-quality teaching resources. Third, the organization guarantee. Although the U$\mathrm{S}$ cooperation is in various forms, the main cooperation subject experts are from universities, excellent principals and teachers in kindergarten. In order to guarantee the benign operation of cooperation, building the efficient organization structure and selecting the appropriate personnel is needed. Fourth is the legal guarantee. In order to ensure the U- S cooperation standardized operation, before the university and kindergarten deciding to cooperate, they should make clear the cooperative target, process, standard and the rights and obligations with the legal form of contract.

\section{Collaboratively Constructing the Modular Curriculum System}

The goals of outstanding teachers' preservice education curriculum are education faith and responsibility education, knowledge and ability, education practice and experience (Gao guiqing, 2015) .In the process of curriculum design, it should follow the integration ideals to achieve the content and time of continuity in the preservice and after serving curriculum, To promote professional development of teacher education. With the concept of "thick foundation, strong ability, integration”, the curriculum design scheme of outstanding preschool teachers' training program should consist of the general course knowledge, professional knowledge, professional skills courses, comprehensive quality curriculum and independent practice courses. In order to strengthen the quality of professional backbone course and practice course, The backbone of the professional courses in outstanding preschool teacher experimental class implement the "curriculum responsibility system", which means that each course is leaded by a rich experience teacher, they are responsible for the teaching outline, teaching plan, curriculum lesson plans, the examination papers, teaching practice.

\section{Collaborative Construction of Vocational Skills “Full Practice” Teaching Model}

"The whole practice training model” refers to the students in the school before graduation, training teacher occupation skills day-to-day and step to step. The practical elements in time delay through whole space. The study place is not only in the university, but also rooted in the practice of kindergarten, the students' professional ability in practice is exercised. Therefore, the students in the outstanding class will have two weeks' practice about children's care education in the second year and 3 week game education practice in kindergarten in the third year, 12 weeks teaching practice in the fourth year. the concept of "the whole integrated curriculum practice" is to enable the ability elements and practice place well integrated, so as to make students before entering kindergarten teaching get education practical knowledge and practical wisdom to develop professional spirit, format the professional ability, create professional character, promote the professional development, practice and improve their professional quality and skills for their future occupation ability. 


\section{Promoting “the Whole Process of Double Tutorial System”}

The whole process of "double tutor system", refers to the students in the excellence class having two professional instructors, one is from the university, the other is from kindergarten. They work Division as well as cooperation to Cultivate and guide the students' professional development. It will be through the whole preservice teacher education process, not only the students enter the practice stage in the kindergarten. The teachers in university guide personally on professional ideas and the theory of knowledge according to the characteristics of the students. The practice tutor in kindergarten mainly focus on the teaching practice ability of students, it make students combine the theory with the specific teaching practice to make up for lack of theoretical study, the students will understand and master the activities and all aspects in the kindergarten better. At the same time, the university instructors and practice instructors should communicate each other frequently, according to the actual situation of students to adjust the guidance plans.

\section{Making a Scientific Evaluation System}

In order to establish a scientific evaluation standard, the evaluation system should include the theoretical knowledge and practical ability. The tutors both in university and kindergartens play the main role in evaluation, as well as the peer evaluation the form of teaching practice evaluation can show with report and discussion, at the end of the second and third year, the students will carry out report and discussion, the tutors will give the scores according their report and discussion. The final practice score is also translated into the corresponding academic performance points, and in the final assessment of academic and theoretical examination scores each accounted for $50 \%$, the students' will be attention to teaching practice.

\section{Acknowledgements}

This paper is supported by the projects of Exploration the U-K Collaborative Cultivating Model of “Outstanding Preschool Teachers”in Local Normal University No.153056; Research on the operation status and optimization mechanism of kindergarten curriculum power,No.15XWB009

\section{Reference}

[1] Gao runqing, The Practice Exploration of Excellent Teachers' Trinity Co-cultivation Model, J. Curriculum Teaching Meterial and Method. 35 (2015)115-120.

[2] Liu Xianrong, Higher Teacher-Education Institutions and Outstanding -Teacher Cultivation Model Reforemation:problems and practices, J. Journal of Zhanjiang Normal College. 33 (2012)45-50.

[3] Shi Yudan,Lu Xiaozhong, On the composition of the quality of excellent teachers, J. Journal of The Chinese Society of Education. 9 (2015)92-96.

[4] Wang Zhiguang, On the construction of evaluation index system of excellent teachers, J. Theory and Practice of Education. 32 (2013)28-32. 